\title{
Toxic Leadership and the Organizational Commitment of Senior-Level Corporate Executives
}

\author{
Majed Yaghi \\ University of Bradford
}

Senior executives are often the tip of the hierarchal spear with skillset, expertise and business acumen that are incredibly vital to organizations. Naturally, they are expected to display high commitment levels to the organization, especially during tough times, like the reign of a toxic leader. This qualitative study examined the nature of organizational commitment through the prism of seven senior executives and revealed four main themes. Overall, circumstantial organizational changes such as the behavior of board members and chief executives, as well as frequent restructuring greatly influences the commitment of senior executives. Furthermore, those senior executives form a symbiotic relationship with their organizations which guides their commitment and consequential reciprocal behavior.

Keywords: Toxic Leadership, Leadership Senior Executives, Organizational Commitment

\section{INTRODUCTION}

Commitment is a thoroughly-studied behavioral construct (Mowday Porter and Steers, 1982; Meyer \& Allen, 1991; Meyer et al., 2004) that continues to interest researchers. However, despite this apparent depth of academic knowledge, there remains much to be learned relative to senior-level executives, their motivation and attitudes. Similarly, there's little knowledge of organizational commitment during the rule of toxic leaders and adverse operating work environments. While a consensus on a definition of commitment remains highly contested among social scientists, one highly referenced definition is that of (Meyer \& Herscovitch, 2001, p. 301) who theorized "it's a force that binds an individual to a course of action that is of relevance to a particular target." The individual could be an entry level position or one of the most senior, it's a psychological state of reference. Something always binds individuals and fuels their drive and growth, we just don't know what it is the binds them.

Moreover, commitment in social science could take on many forms including organizational commitment, personal commitment to a team, and commitment to a profession. However, how commitment is manifested in a toxic workplace or under the reign of toxic leaders is less defined. Specifically, we don't know if commitment changes depending on the leadership style of superiors or even if commitment varies based on the individual's seniority within an organizational context. As a novice researcher and after spending two decades in corporate roles with global multinationals, the lack of research in this field is even more concerning, especially given the practical need for such insights. Additionally, practitioners have often looked to science for knowledge, for validation or support to some of the most significant strategic organizational decisions to be made. 
In an organizational context, commitment can be described as an employee's connection to their employer, their level of buy-into the company's strategic direction. It is representative of the level of alignment between the individual's values and beliefs and those of the company they work for. As such, commitment is a psychological state of mind and because of this emotional connection it's imperative to understand how commitment plays out in the psyche of senior-level executives, those who are privy to the inner workings of organizations and those with compensation packages that have come under scrutiny recently for its sheer size and scale.

This exploratory qualitative research study was conducted with the purpose of understanding the influence of leader's behavior on the organizational commitment of senior executives. To maintain objectivity and avoid research bias, interview questions were contextualized in broad leadership terms and avoided any explicit reference to toxic leadership or toxicity. Study participants were all asked the essential research question "How would you describe your personal commitment level to your current employer?" The argument being that senior corporate executives would be expected to demonstrate higher levels of organizational commitment than the average employee. Their proximity to strategic decision making, their expertise, their seniority level, and distinguished compensations, are only few of the reasons their commitment is anticipated to standout.

This paper will first present a review of the literature on both commitment and toxic leadership, followed by the research methodology applied in this study, data collection, findings from this qualitative study, and a discussion of the study's key findings. Finally, implications to research and practice are outlined for future reference.

\section{LITERATURE REVIEW}

Meyer \& Allen, (1991 p.539) posited commitment is "a psychological state that (a) characterizes the employee's relationship with the organization, and (b) has implications for the decision to continue or discontinue membership in the organization." Much of the academic work in this field references one of two seminal studies, (Mowday et al., 1982 and Meyer \& Allen, 1991) and both agree commitment is what binds an individual to something of importance. In an organizational context, the workplace, could bind one employee while in a personal context, an objective or a goal could bind another.

Meyer \& Allen (1991) developed a 3-component conceptualization of organizational commitment, a desire, an obligation, and a need. The desire (affective commitment) represents the attachment an employee has to their employer or place of employment. According to (Mowday et al. 1979), affective commitment is the relative strength of an individual's identification with and involvement in the organization where they work. Meanwhile, the obligation component (normative commitment) reflects the employee's sense of obligation to remain at the organization. This normative commitment may also develop when an organization provides the employee with "rewards in advance" e.g. covering the employee's university fees or providing training or professional accreditation. Finally, the need component (continuance commitment) denotes the employee's necessity to maintain their employment because the costs associated with suspending that relationship are too prohibitive. In this continuance context, what merely binds an employee to the organization is the financial benefits, not identification with the company's goals or values.

Meanwhile, toxic leadership is a relatively new domain to the academic field of leadership study likely popularized during the past two decades by the increasing destructive behavior of political (e.g. Reed, 2004; Lipman-Blumen, 2005) and corporate (e.g. Padilla et al., 2007; Goldman, 2008) leaders. One of the early references to the term "toxic leadership" was (Whicker, 1996 p.11) who described corporate leaders that are "maladjusted, malcontent, and often malevolent, even malicious people who succeed by tearing others down and engage in turf protection, fighting and controlling rather than uplifting followers." However, for the purpose of this study, when referring to toxic leadership, Padilla et al., (2007) tripartite contextualization is the reference point. Padilla et al., (2007) posited a "toxic triangle" emerges when three negative forces converge on an organization, a toxic leader, a group of susceptible 
followers, and a conducive environment. Therefore, toxic leadership in this paper will refer to the amalgamation of those three factors, i.e. toxic leaders, toxic workplaces, and toxic workers.

Much of the existing harmful leadership research have focused on either understanding the antecedents of toxic leadership or developing a taxonomy of the various constructs in that domain. There is little evidence of the consequences of toxic behavior or organizational effect it leaves behind. During the past two decades an abundance of corporate and political scandals have brought toxicity to the forefront of our vernacular and entire organizations such as Lehman Brothers, Enron, and others were destroyed due largely to the harmful behavior of their respective leaders. Some evidence does exist (e.g. Tepper, 2000) showing lower commitment levels when abusive supervisors practice positional injustice. Also, (Mathieu, et al., 2014) found supervisory behavior had an effect only on job satisfaction but not employee commitment. However, much else of the existing academic research remains limited or unknown, like what happens to commitment when that employee is a senior-level executive, or a chieflevel company officer who reports to the organization's CEO or Board of Directors. That is the main gap this research study is addressing.

\section{RESEARCH PURPOSE}

Current literature presents an overarching theoretical perspective on the general influence of leadership on commitment but does not delve deep into toxic leadership. More specifically, the role a leader's toxic behavior plays into the commitment of senior executives can both inform the broader discourse, as well as help practitioners implement better HR policies and practices.

This paper describes perspectives of senior executives on how toxic leadership behavior influenced their commitment level and the dynamics surrounding that experience. The focus is on senior executives distinguishes this study from others which have often approached the subject of employee commitment from an associates' perspective. Lower commitment leads to dissatisfaction and eventually turnover, which for senior-level executives is both untenable and expensive.

Yucel et al., (2014) reported the turnover costs associated with top-level executives are far greater than those of lower ranks, thus reinforcing the need for HRMs to ensure the commitment level of those senior executives is monitored closely and maintained at a desirable level. With their average salaries being several times multiple of the average worker's salary, even if the cost of turnover is $30-50 \%$ as reported by some, the financial burden on the organization could be significant. MacLennan, (2017) in a case study of a toxic leader's behavior calculated the cost of turnover for director-level positions to be close to $\$ 197,976$. Either way, the cost of losing a senior executive including their skills and subject matter expertise are far too significant for organizations to overlook or possibly sustain. Park \& Shaw, (2013) highlighted additional organizational costs of turnover such as recruitment, selection, and training, all of which would be proportionately higher for senior-level executives.

\section{RESEARCH METHODOLOGY}

This research study is only the qualitative component of a larger mixed research methods project that explored the organizational influence of toxic leadership behavior. The qualitative research was the first phase of that project and findings from this study helped inform phase two of the parent project which included a quantitative study that provided empirical evidence to support the research objectives.

For the qualitative phase, the scope of this paper, snowball sampling was applied to recruit a total of ten executive-level individuals for this study. However, three individuals were never able to coordinate a suitable time due to their international travel schedule. That said, the final number of participant was seven executives representing several industries such as consumer packaged goods, media, services, retail, and technology. Participants also represented a wide range of organizational size, from a small startup to conglomerates with over 10,000 employees. Finally, no compensatory benefits of any types were provided to any of the participants. 
Semi-structured interviews were the main source of primary data. Seven one-hour interviews (Table 1) were conducted face to face between July and October 2018. Since the quantitative phase of the parent project included a quantitative study of 342 survey questionnaires, a total of seven in-depth interviews in phase one was sufficient to fulfill the desired objective.

TABLE 1

INTERVIEWEE PROFILES

\begin{tabular}{|l|l|l|l|l|l|}
\hline REFERENCE & GENDER & $\begin{array}{c}\text { AGE } \\
(\text { est. })\end{array}$ & \multicolumn{1}{|c|}{ TITLE } & \multicolumn{1}{|c|}{ INDUSTRY } & $\begin{array}{c}\text { NO. OF } \\
\text { EMPLOYEES }\end{array}$ \\
\hline QA-R1 & Female & $50-55$ yrs. & Director of HR & Consumer Goods & $10,000-15,000$ \\
\hline QA-R2 & Male & $45-50$ yrs. & Chief Executive Officer & Hospitality & $1,000-2,000$ \\
\hline QA-R3 & Male & $50-55$ yrs. & Chief People Officer & $\begin{array}{l}\text { Corporate } \\
\text { Tax Services }\end{array}$ & $5,000-10,000$ \\
\hline QA-R4 & Female & $50-55$ yrs. & Chief Marketing Officer & Consumer Goods & $10,000-15,000$ \\
\hline QA-R5 & Female & $25-30$ yrs. & Director of Sales & $\begin{array}{l}\text { Technology } \\
\text { Startup }\end{array}$ & $100-150$ \\
\hline QA-R6 & Female & $40-45$ yrs. & VP-Marketing & Retail & $5,000-6,000$ \\
\hline QA-R7 & Female & $45-50$ yrs. & Chief People Officer & Media & $10,000-15,000$ \\
\hline
\end{tabular}

As a courtesy to the study participants, they were provided with an advanced copy of the interview guide (Figure 1.) Few participants requested to see the interview questions prior to confirming their willingness to take part in this study. Given their time busy schedules, having access to the interview questions beforehand allowed the participants to be better prepared as well as be more at ease during the actual interviews. The interview guide included a set of six primary questions that helped navigate the interviews and probe into key research areas in a semi-structured setting. Those questions, naturally openended, encompassed the main theoretical areas of interest that emerged in the literature review. The questions were separated into three groups with the first one being demographic and background information to understand work and role scope of responsibilities. The second group of questions focused on the interviewee's managers, their work environment, and co-workers. The third and final set of questions focused on commitment to work.

Moreover, all interviews were conducted in English and reordered digitally using a mobile application that was downloaded free of charge. This enhanced the validity and reliability of the collected data and allowed the research more time to listen and watch for any nonverbal cures. Nordstrom, (2015) suggested that for the interview to be valid "it is ideally recorded" and as such permission to record was sought and granted from each participant prior to the start of interviews. One other driver of validity for this study was the diversity of industries those participants represented. Finally, transcription of interview material was completed via a professional online transcription service offered by that same mobile application for a nominal fee. 


\title{
FIGURE 1 \\ INTERVIEWE GUIDE
}

\author{
Interview Questions
}

Demographic and Background Information:

Q1. Can you please tell me a little about yourself, work background, role \& responsibilities? Probe: Do you like working there? Why?

Leadership and Work Environment:

Q2. How would you describe your manager, both as a person and as a supervisor? Probe: How would you describe his/her leadership style? Can you please give me one thing you love/admire and one that you dislike about your manager's leadership style and why those in particular resonate with you the most?

Q3. Now, thinking about the place where you work, could you please describe for me your workplace environment (how well it develops, engages, empowers, and motivates you)?

Commitment:

Q4. How would you describe your current personal commitment level to X (Place of employment)? Probe: To what extent has this commitment level changed recently and why?

Q5. What role does senior management behavior play in driving your commitment to work? Probe: In what way is your commitment driven by your relationship with your current manager?

Q6. What role does workplace environment play in impacting your commitment to work? Probe: To what extent have your level of satisfaction changed over the past couple of years?

Following the completion of the data collection stage, interview transcript reviews (ITRs) were emailed to the participants, both as another quality assurance measure and to enhance the rigor of the study. Each study participant reviewed transcripts of their respective interviews and confirmed via email their accuracy. No comments or edits were made to those transcripts.

\section{FINDINGS}

Based on the findings from this study, a thematic model is presented herewith which captured and encapsulated the stories and experiences shared by those senior executives. Six of the seven interviewees appear to have recently left job voluntarily and largely driven by the behavior of toxic leaders. Behavior perceived as toxic by participants impacted their individual commitment levels and had significant influence on the day to day operations of organizations and ultimately their decisions to leave or remain with those organizations.

In a way, leader's toxic behavior appears to be both a barrier and an enabler. It's a barrier when senior executives are not empowered to do their work, and the leader's action derails progress. It's also an enabler when organizational change is frequent and senior executives demand clarity from their leaders. When we think of leaders we think of managers who have a team of subordinates working under their direction, but when we think of senior executives, we're referencing senior leaders at the top of organizational hierarchy. They lead other people leaders and command a significant amount of power. However, senior executives do not appear to be immune to toxicity themselves, as apparent from the following story an interviewee shared about having a toxic boss: 
"I had no autonomy or authority at all to make decisions and so in theory I was the person responsible for setting direction and for making decisions but the situation with respect to leadership was the complete opposite. I was not supported, and I was micro managed even at a very high level, I would even go so far as to describe it as toxic. It seems almost laughable at this level, but it was almost like an abusive relationship." Participant 7 (Chief People Officer)

It appears this CPO was negatively impacted by the repeated behavior of their toxic boss who incidentally was the company's CEO. Being micro-managed while also lacking support from their boss complicated their relationship, especially for a chief people officer whose main role is leading change and impacting people policies.

Organizational change could be a good thing and may even result in enhancing employee commitment, possibly moving someone's commitment from continuance to normative and another from normative to affective commitment, when they are bound by their work and organization, both emotionally and physically. Indeed, affective commitment exemplifies the strong connection between employees and their organization, its values and beliefs in a profound way, as one study participant exclaimed:

"I would say my commitment is high right now. There's so much really positive work that we're doing right now. It's pretty interesting but from an organizational standpoint, we're in the right place." Participant 3 (Chief People Officer)

The participant is clear in their strong sense of belonging to the company, after what they considered was a large-scale organizational change (roughly $11 \%$ of their workforce was enticed to take a lucrative severance package), they highlighted the motivating nature of the work they're currently do. Furthermore, their optimism is evident in their opinion of the company's prospects, which they attributed to the boss (company CEO) who was recognized as one of the top executives in the America. Clearly, under great leadership, it is not surprising that commitment of senior executives would at the highest (affective) level.

Analysis of the study's research data identified major drivers that influence the commitment level of senior executives in a toxic leadership context. Those drivers have been grouped into six overarching themes, forming the thematic model for senior-level executives' commitment to toxic organizations as shown in figure 2 below. 


\section{FIGURE 2 \\ OVERARCHING THEMES}

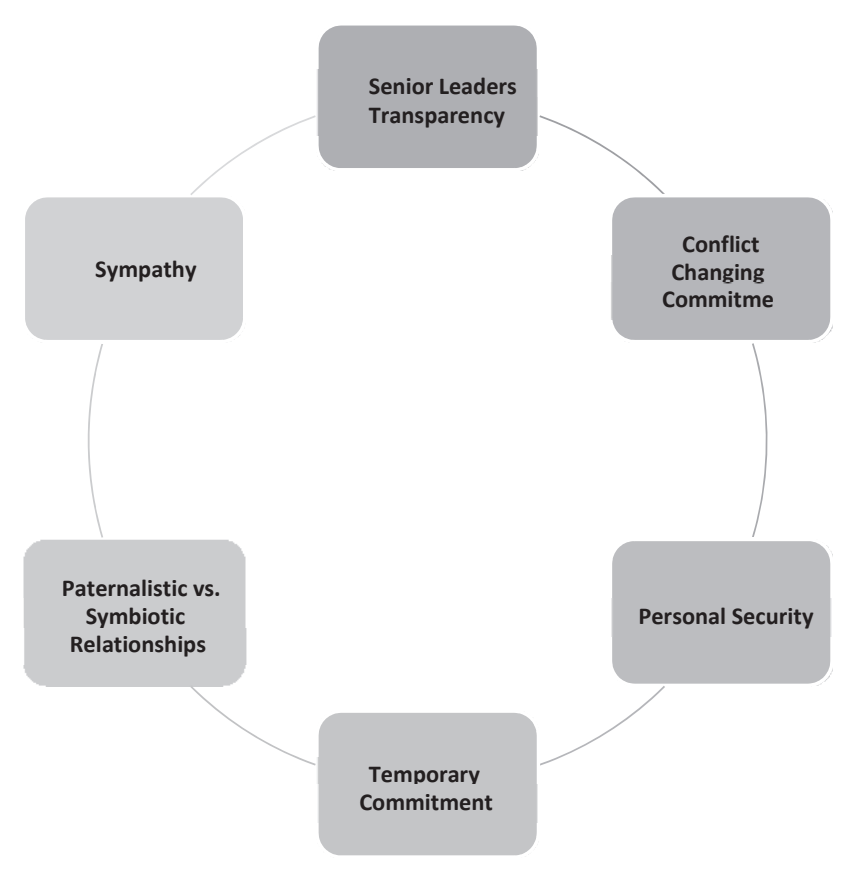

\section{Theme 1: Transparency}

Participants were very vocal about transparency, or lack thereof, from their managers (CEOs, CMOs, and $\mathrm{BoD}$ ) and indicated it was critical to their personal commitment to the organization where they work. High importance was placed on honesty to support the overarching positioning of leadership as a beacon of hope and reinforce the organizational culture. One participant, a Chief People Officer, recalled how a subculture evolved when transparency was missing and the countereffect of such toxic behavior were often severe.

"The CEO's role is not to tell everyone in the organization what their roles are, but he understands the importance of surrounding himself with people who are successful and who are positive and supportive and who know their stuff and trust them to do their jobs. We don't have that in some pockets of organization and leadership is not strong, lacks transparency and the communication is poor and it's like a sub-culture within, which is really upsetting for me because it runs completely counter to what it is we're trying to create." Participant 7 (Chief People Officer)

The participant recognizes existence of communication gaps within some departments or divisions of the company. Being the organization's chief people officer adds a deeper perspective to what they envision as a threat to the company's overarching culture. Lack of transparency from the division head is not in line with organizational expectations, but the presence of a toxic division president amplifies the disconnect between the two cultures.

Senior leaders are entrusted with making tough decisions that profoundly impact every aspect of business. Powered with all the tools and information needed to make big decisions, they thrive on being decisive. However, operating under toxic leaders, some decisions senior executives make could have different consequences. The following lengthy excerpt from one of the study's participants was intentionally selected for its reflection of senior executives struggle with toxic leaders. The participant, who is a chief marketing officer of a large international organization said: 
"As a leader I could decide to go with or against the company's line on something like transparency for example. I could hide behind that and keep information from my team or I could draw the line and say I'm not going to keep information from my team. If I do that, then I'm setting the tone and therefore creating a totally new culture within my own team, that is unbeknown to the CEO and board. I chose the latter, I chose to be honest and fully transparent with my team, because that's just how I am and that's how my team was. Those are the values I held as a leader of my team. I just told them, look this guy is planning to do this so get your stuff in order and prepare for the worst. I couldn't lie to them and say everything was all right when it wasn't. Participant 4 (Chief Marketing Officer)

Participant 4 objected to the CEO's approach and instead chose what they considered to be the right thing to do. Their story demonstrates personal commitment and commitment to the team. Deeply-held values and personal beliefs guided their decision making, even when it clashed with their boss's desires, in this case, In this case, the boss (Group CMO) was planning to implement large-scale restructuring of the organization with severe impact on the participant's own marketing team. Being an ethical leader, the participant rejected withholding such information from their team and chose to warn them of what was laying ahead and the changes were being made. The participant expected their boss to be more transparent, especially since there were legitimate business reasons for change. Participant chose to be more transparent than their boss.

Drawing a hard line between what was viewed as unethical behavior from their bosses on the one hand and their core personal values and beliefs on the other, several participants articulated the importance of transparent communication from senior leaders. They expect the same level of candor for both positive and negative news. Incidentally, for participant 4 the changes took place as planned and led to the elimination of the function entirely and termination of all team members. What the participant missed, or was not informed by the CEO, was the chief marketing officer position would eventually be eliminated and restructured into a new role. They rejected the new role and opted to leave that organization. Whether it was intentional deception by the toxic CEO is unknown, albeit plausible.

\section{Theme 2: Post-conflict Changing Commitment}

Study participants reflected a theme of changing levels of commitment which they attributed to some negative events at their workplace such as change or repeated negative behavior. While high commitment levels such as affective commitment is grounded in personal belief of company's mission and values, normative and continuance are more short-term and transactional. Depending on the circumstances, shifting commitment could be positive or negative, as in the case of study participant 6 who noted:

"I was so excited to join this small brand. I honestly believed they had a strong opportunity to take a leadership position in their segment. I saw the brand as trendy and very innovative, so I thought I could make a huge impact and take the brand somewhere higher and faster. I did not foresee the strong resistance from within and I certainly did not expect to get resistance from the board. So, I would say I was very committed before, but now it's a different story. I will be leaving this company in few months and so my commitment is just to see through the next few months and hope we don't kill each other." Participant 2 (Chief Executive Officer)

Participant 6 shared a story of joining a small organization as CEO and being excited about the opportunity to leave $n$ impactful imprint but was faced with opposition from within the company's board of directors. Even as the CEO of the organization, they saw their attempt to implement new strategic direction blocked by the toxicity of some board members. The board members were exerting power over the new CEO. Unfortunately, the periodic conflict with board members and declining commitment to 
work led participant 6 to make their eventual decision to leave. Garry, (2019) highlighted board members can be toxic but also are not easily fired, so chair of the board of directors must manage this delicate process and strategically reduce the power of toxic board members until their eventual departure or voluntary resignation.

Another participant (VP-Marketing) recalled how both their own commitment as well as that of their direct reports changed due to organizational transformation by saying:

"It was a tale of two cities, so when I started things were decent, they weren't terrible but decent and later things changed. We pretty much went through annual layoffs and so the company culture really went from business as usual to panic mode. So, people were worried, are they going to make it to the next round or not. I knew my team members were looking for work outside of the company, so I had to lower my expectations of what they can deliver honestly. So I knew their commitment to work has changed, just as mine did, and it's hard not to when the organization is not stable and having layoffs that frequently." Participant 6 (Vice President of Marketing)

The participant described how frequent organizational changes changed not only their personal commitment to the company, but also that of their team. The collective decline of commitment had an apparent adverse effect on work productivity, as expectations had to be lowered. There's no telling what the valuation is of this lost productivity but for a large organization like the one that participant led, regardless of the cost, the situation was not tenable. As the organization shifted from normal to panic mode, employees, even senior-level executives, switched their commitment from work to personal job security.

The frequent organizational restructuring damaged morale and destabilized operating teams. This one team immediately started looking for career options outside their company, soon after they heard of the most recent round of layoffs. Personal job security trumps organizational commitment which is even more pronounced in tough employment markets.

\section{Theme 3: Personal Security}

Normative commitment reflects a sense of an individual's obligation toward their employer. It's a sense that often emerges as an outcome of the employer providing an employee with special benefits or some type of value added, as an incentive or reward. At the senior level, top executives receive generous compensation packages and numerous benefits that would merit commitment levels stronger than average employees. In either case, because of such incremental benefits, employees feel obligated to remain with their organization as gratitude or reciprocity. This can be seen in the following story from one of the participants:

"I love it here and the behavior senior leaders model. For example, I was encouraged to do this leadership development program, despite the business decline. I asked my boss if I still should go because it's costing the company so much money and he said yes absolutely. He said we'll figure out the funding on the back end. He made my development a priority over budget. I definitely feel my commitment is stronger to the company and now I'm kind of obligated to work harder and be a better and more loyal employee." Participant 6 (Vice President of Marketing)

The participant had no qualm about linking their organizational commitment to the exceptional benefit they received recently from their employer in the form of a manager's nomination by to participate in an elite leadership development program, summit leadership. They described it as a yearlong, company-sponsored career advancement platform designed and managed by a highly reputable third party. The program is dedicated to the company's top echelon and is estimated to cost hundreds of 
thousands of dollars per head. It provided the participant with an attractive career enhancement and job security, and as such merited the strong commitment.

Despite the economic hardship the participant cited facing their company, a supportive manager (The CEO) was instrumental in that personal growth opportunity. Furthermore, they exclaimed loyalty to the organization and their motivation to work harder now as a way of paying back the organization for this great benefit. If the circumstances continued to be positive for that participant, it is likely they would develop even stronger levels of commitment, maybe even emotional connection and their commitment to the company may evolve from normative to affective. Conversely, the participant may feel after few years, that their dues had been paid back to the company and a decision to seek employment elsewhere may ensue.

Another perspective on personal security is the role of compensation that a senior-level executive expected or demanded from their employers as one participant articulated:

"I don't have equity in the company and so when we're sold in four or five years I don't know what that will mean for me personally. I think about the way I'm compensated, the benefits and things like that. I have a 3-year old and I'm married and live in the suburbs and so that's really important to me." Participant 7 (Chief People Officer)

The expectations of having equity in the company to the participant was important to their sense of security and hence their overall commitment to that organization. In this case, their commitment is for their own family. Moreover, the story highlights the proximity such senior executives have to strategic plans such merger \& acquisitions, and other inner corporate workings. Yet, their senior position did not change their commitment in a positive way.

\section{Theme 4: Temporary Commitment}

Senior-level executives appear to show temporary organizational commitment despite their seniority and leading role in motivating and stabilizing their employees. This temporary commitment could be considered a form of continuance commitment which represents the lowest level of organizational commitment. Continuance commitment also reflects a dangerous stage of the relationship employees have with organizations. It is temporary in nature, meaning individuals senior executives are only committed because of the absence of other viable options or until another career opportunity surfaces and they could them a resignation. Continuance commitment tends to be associated more with toxic leaders who are not people-centric and those that do not work with their deputies to inspire and motivate them. Take participant 4 as an example:

"I was just holding on until I found something else. Man, we're all fine and doing our own things, so to me it's the company that lost all that talent and expertise." Participant 4 (Chief Marketing Officer)

While the participant was privy to company plans of an imminent large-scale restructuring, they were able to both alert their subordinates of the forthcoming plans, as well as begin searching for jobs elsewhere. Provided they were all on payroll, their commitment to the organization was still there, i.e. to the job itself. The participant was likely not fully committed before or after the restructuring. Moreover, the participant reiterated their team of direct reports (they were made redundant during an organizational redesign) had all landed other jobs outside the organization, insinuating the company was the ultimate loser in that forgone relationship. Such temporary commitment in this example was more favorable for the individuals who received full pay and benefits until they found new jobs, but it was also probably detrimental to the company as performance and productivity could have been minimized during that period. 
Another participant linked their temporary commitment to their company's general investment in human resources as an example of the company lacking commitment to their employees. They commented:

"Well, there wasn't any commitment at all, for multiple reasons. One, they weren't investing in us, there wasn't any training, they weren't developing us anymore." Participant 6 (Vice President of Marketing)

In this case, commitment was lacking entirely during the tenure of the toxic CEO, who scaled back investment in many function including people. Regardless of reasons, organizationally the outcome of such negative experience was turnover as the senior executive resigned as soon as they found a better job.

Another study participant shared how their commitment changed with the arrival of a new manager, someone they described as being toxic in nature. They commented:

"Now, my commitment might change if the behavior of my manager changes and he starts acting more like the previous VP, but that's very doubtful." Participant 5 (Director of Sales)

There is a level of understanding, that every leader carries into any leader-follower exchange, but toxic leaders appear to break the mold when it comes to organizational norms. Indeed, temporary commitment is often linked to employees' desire to leave and seek employment elsewhere, but it is magnified in a toxic environment. In a way, a leader's toxic behavior pushed certain senior executives over the edge, causing them to leave.

\section{Theme 5: Paternalistic vs. Symbiotic Relationships}

Some individuals articulated a holistic approach to commitment expecting the link between them and employers to be paternalistic. They expected both company and employee to exchange a mutuallybeneficial long-term promise to one another. This concept might be foreign today, especially with a new and younger generation in the workforce, but for some senior executives there is a level of reciprocity expected when they are hired, as one participant said:

"Commitment to a company worked when it was paternalistic when I knew I was going to get retirement, benefits, etc. But when you take the free agency approach which means the next reorganization you could be out, whether you're a high performer or not, because again they have that power, how could you talk about commitment, because in free agency the person is only committed to that contract. It's short term." Participant 4 (Chief Marketing Officer)

More likely driven by the participant's long work history with large global organizations, their stories overtly demonstrate the divide between long tenured senior executives who expect loyalty back from their employers and young executives who may prefer the short-term commitment. The participant was vocal about the bereavement of commitment as an organizational concept in today's corporate universe. Attributed to the frequent restructuring and constant shift in compensation and benefits, the participant advised corporations to shift their focus away from commitment and focus on performance instead. Focusing on business results would be a better match to the short-term nature of today's business world.

Senior executives are often expected to demonstrate advanced levels of alignment with organizational direction and priorities. So, it comes as a surprise when a participant reflects an interdependence on leader behavior.

"There's no commitment to the company because it's all about WIFM (What's in it for me)" Participant 6 (Vice President of Marketing) 
"I've also have had conversations where we've done stay interviews with folks where they say I was uncertain before about the direction of the organization but now I believe in my manager and they keep me close and they tell me what's going on and I respect them and I trust them and so I'm going to wait it out and I'm going to see what happens as long as that relationship is strong that is kind of the anchor point for someone even if there's a little bit of uncertainty issues or things that are not positive in the other parts of the organization." Participant 7 (Chief People Officer)

This reciprocal nature of participant 6 story highlights the role toxic leadership behavior plays in influencing employee commitment. Working under the leadership of a toxic manager, senior executives are faced with limited options that range between leaving the organizing or sustaining the toxicity and remaining with the company. Commitment for those executives who remain would be expected to decline, as in the case of participant 6 , or might increase for employees who condone such destructive behavior. WIFM is corporate jargon for "it's all about me" in which case commitment is to one's personal needs and not the organization. In either case, business results would suffer and the organizational effect is considerable.

Another perspective demonstrates the dichotomy facing organizations today as they search for improving employee commitment and engagement. The participant noted the symbiotic nature of their commitment to the previous employer before they gave up and decided to quit. There is no doubt that employees in general often make tradeoffs at work and in this case, commitment to the organization appears contingent on the leader's behavior. If the manager shows more transparency and respect toward their subordinates, the employees in turn will reciprocate with trust and commitment. This symbiotic relationship could be short-sighted and negatively affect organizations. That said, for senior leaders who aim to build an effective organization, such levels of commitment from senior executives especially their deputies, should be alarming as it is not conducive to achieving great business results.

\section{Theme 6: Sympathy}

The final dimension of senior executives' commitment is sympathy as articulated by this study's interview participants, especially those who resigned and left those toxic organizations behind. The feeling of consideration to what could have been was startling. Most of the stories shared included an element of compassion for past employers and their brands raising the question of what could have been. One participant recalled:

"We were all sad about it because we loved the brand and loved what the brand represented, families getting together and picking out a movie, spending time together, date night, and all of that good old days. And then just seeing the brand become what it had become, were all saddened by that." Participant 6 (Vice President of Marketing)

Reflecting on their work experience at a former employer, a company that no longer is in business, participant 6 reminisced about what the company and its brand stood for, the values the participant experienced not only as an employee, but also as a consumer of that brand. The participant reinforced their negative experience by overlaying their personal sympathy for their other colleagues who witnessed a toxic CEO destroy a 30-year old organization with thousands of employees and thousands of nationwide retail stores.

Senior executives aim to protect their professional legacy and strengthen their personal brand. Some choose jobs that specifically match their skills and bring $100 \%$ effort to work.

Unfortunately, toxic leaders tend to destroy much of that value with no sympathy for the organization or people. Study participants were clear in their feeling toward past employers and the sense of huge loss in human capital, as evident by the following excerpts: 
"I mean I loved what I was doing and my team. I loved it and I honestly felt like I owned the company, but when he (former boss) came along, it all changed." Participant 4 (Chief Marketing Officer)

"I really loved the energy, autonomy and innovation and used to be very excited to come to work every day. I wanted to see the company succeed and grow because I enjoyed my work and felt that my work was contributing to the company's growth." Participant 5 (Director of Sales)

Both Participant 4 and 5 communicated their affinity to their past work and former teams. It can be argued that both were effective at their respective jobs. While their descriptions fit the criteria of affective commitment, the participants associated their eventual departure from the company to the arrival of their toxic leaders at the time. Indeed, toxic leaders and their behavior have a holistic role on organizations and losing talented and passionate employees is costly on several levels.

\section{DISCUSSION}

The emergent results of this qualitative study provide insights into how a variety of dynamics play into the organizational commitment of senior-level executives during toxic leadership. The study findings suggest toxic leaders, or a toxic workplace would have an adverse effect on the organizational commitment of senior executive and lead them to leave. Moreover, findings suggest the commitment level of senior-level executives is not constant or to be taken for granted because of their seniority or sizeable compensation. Commitment of senior leaders could change depending on the circumstances of the organization or negative behavior of the leader. Additionally, just because they're senior level does not appear to secure their automatic organizational commitment.

The resulting thematic model from this research identified six critical themes which represent the foundation for the organizational commitment of senior executives. Transparency of leaders was an apparent priority for senior executives, as it hits at the heart of organizational culture. Gatling et al., (2017) found a relationship between leader transparency and behavioral integrity of trust in the leaderfollower relationship. This study's participants reiterated the need for transparency from their leaders as a pre-requisite for their total commitment to the organization. In the meantime, their commitment will be directed to personal targets like themselves or family.

Personal security is also important to senior executives as they aim to protect their professional credentials from the harm a toxic leader inflects. As (Basu, 2017) suggested, senior talent appears to choose job security above pay. This study's participants demonstrated some of that same mindset. Indeed, participants shared highly-personal stories of their dealings with toxic leaders and their effort to defend the threat.

While some of those senior leaders expected a paternalistic relationship with employers, they came to the realization that only a symbiotic was possible. Shufen, S. V. (2016) posted that unlike previous generations, Gen Y does not believe in the concept of paternalistic relationships between employees and their employers because of today's dynamic work conditions which predicates agility and quick adaptation to change. One noteworthy discovery from the narrative of study participants was the reciprocal nature of commitment for senior-executives and their disposition to exchange their corporate allegiance for some form of value, either long or short term.

Ashforth, (1994 p. 7) noted "the relationship between a tyrant and their subordinates if often based on a calculated exchange of services" meaning both parties to this leader-member exchange are explicit in their symbiotic relationship. Senior executives in this study did not appreciate the symbiotic nature of their relationships with toxic leaders, although they accepted it and adapted.

Much of those dynamics surrounding the commitment level of senior executives during toxic leader reign are not different from those of the average employee. If someone is not committed, they are unlikely 
to remain with an organization. However, the magnitude of financial and human capital losses associated with senior executives turnover is far too severe.

General findings from this study reinforce (Meyer \& Allen, 1991) 3-component commitment framework with study participants sharing stories that reflect all three types of commitment, affective, normative, and continuance. It may be difficult to fathom, but not all senior-level corporate executives exhibit affective commitment and in fact some exhibited high levels of continuance commitment. Nonetheless, the findings also demonstrate the practical reality of human behavior whereby commitment levels do not vary based on organizational seniority. Senior level executives are humans after all and they strive to protect their jobs and legacies.

\section{LIMITATIONS}

This study is not unlike other academic work and there are two main limitations associated with the study design, being part of a larger study to evaluate the influence of toxic leadership behavior. Firstly, only seven individuals were interviewed for this study and while that may not have satisfied the need for thematic saturation, the insights generated from this study helped inform part two of the larger study, the qualitative phase. Secondly, given the seniority level of the participants, time allocated to the interview was limited to 60 minutes which restricted the researcher's ability to probe on certain important areas. Finally, five of the seven participants were females which may have skewed the study especially since Gonzales, (2016 p. 172) posited "women tend to have an interdependent self-construal and a relational identity orientation" and as such are likely to associate less with bureaucratic culture.

\section{CONCLUSIONS}

The study aimed to explore the influence of toxic leadership behavior on the commitment level of senior-level corporate executives. Findings from this study suggest that circumstantial changes in the organization such as behavior of board members and CEOs, as well as unexplained frequent organizational restructuring greatly influence commitment of senior executives. Senior executives seem to expect and demand transparency from CEOs and Boards of Director. Organizations must not take the commitment of senior-level executives for granted because protecting their professional experience and personal brand is key. This cohort showed a need for personal security and transparency in order to be effective at their strategically important roles. Furthermore, when recalling the experience of resigning a senior-level position, study findings showed that senior executives felt a sense of sympathy for their former employers and the associated significant human loss. The decision to voluntarily quit is a tough one, but it appears to be even more difficult for senior executives as they grabble with it.

Senior-level executives echoed an understanding of the transactional nature binding executives to the organizations and as such a symbiotic relationship is formed and guides their commitment and reciprocalcentric behavior. Unfortunately, a senior executive's commitment predicated on short-term thinking is not a recipe for success and organizations must take notice.

\section{IMPLICATIONS}

This study supports (Frost, 2004 p.113) who found that "people are not able to or choose not to put their emotional and intellectual energy into work issues. They withdraw their commitment and their loyalty to their company, and everybody loses out." Senior-level executives in this study echoed such sentiment but all of them chose to leave a toxic leader rather than stay and collude with such negative behavior. Additional research is needed to understand other aspects of the senior-level leaders cohort and especially their organizational influence.

Study findings have implications for practice as well with the most significant being the need for transparency from leaders, both with their deputies (this study's participants) and the general masses in the organization. Additionally, CEO and board of directors should not take the commitment of senior 
executives for granted and despite their generous compensation packages, they have fundamental needs that must be addressed by the organizational leadership. The reciprocal nature of an apparent symbiotic relationship they have with the organization, means cost of replacing senior executives would be significantly higher than average employees. Such a financial burden requires careful planning from the organization.

\section{REFERENCES}

Ashforth, B. (1994). Petty Tyranny in Organizations. Human Relations, 47(7), 755-778.

Basu, S. (2017). Senior Talent Chooses Job Security Above Fat Pay or Startup Experience Jobs. The EconomiTimes. Retrieved August 15, 2019, from https://search.proquest.com/docview/1871657521?accountid=17193

Frost, P. J. (2004). Handling Toxic Emotions: New Challenges for Leaders and their Organization. Organizational Dynamics, 33(2), 111-127.

Garry, J. (2019). How to Fire a Toxic Board Member. Retrieved August 19, 2019, from https://blog.joangarry.com/how-to-firea-board-member/

Gatling, A., Shum, C., Brook, L., \& Bai, B. (2017). The Influence of Hospitality Leaders' Relational Transparency on Followers' Trust and Deviance Behaviors: Mediating Role of Behavioral Integrity. International Journal of Hospitality Management, 62, 11-20.

Goldman, A. (2008). Company on the Couch: Unveiling Toxic Behavior in Dysfunctional Organization. Journal of Management Inquiry, 17(3), 226-238.

Gonzales, J. A. (2016). Demographic Dissimilarity, Value Congruence, and Workplace Attachment Asymmetrical Group Effects. Journal of Managerial Psychology, 31(1), 169-185.

Limpan-Blumen, J. (2005). The Allure of Toxic Leaders. New York: Oxford.

Maclennan, H. (2017). The Cost of Toxic Leadership: What the Board Didn't See. Journal of Leadership, Accountability and Ethics, 114(4), 100-104.

Mathieu, C., Neumann, C. S., Hare, R. S. \& Babiak, R. (2015). A Dark Side of Leadership: Corporate Psychopathy and Its Influence on Employee Well-Being and Job Satisfaction. Personality and Individual Differences, 59(2014), 83-88.

Meyer, J. P., \& Allen, N. J. (1991). A Three-Component Conceptualization of Employee Commitment. Human Resource Management Review, 1(1), 61-89.

Meyer, J. P., Becker, T. E., \& Vandenberghe, C. (2004). Employee Commitment and Motivation: A conceptual Analysis and Integrative Model. Journal of Applied Psychology, 89(8), 991-1007.

Meyer, J. P., Stanely, D. J., Herscovitch, L., \& Topolnytsky, L. (2002). Affective, Continuance, and Normative Commitment to the Organization: A Meta-Analysis of Antecedents, Correlates, and Consequences. Journal of Vocational Behavior, 61, 20-52.

Mowday, R. T., Porter, L. W., \& Steers, R. M. (1982). Employee-Organization Linkages: The psychology of Commitment, Absenteeism, and Turnover. San Diego, CA: Academic Press.

Padilla, A., Hogan, R., \& Kaiser, R. B. (2007). The Toxic Triangle: Destructive Leaders, Susceptible Followers, and Conducive Environments. The Leadership Quarterly, 18, 176-194.

Park, T. Y., \& Shaw, J. D. (2013). Turnover Rates and Organizational Performance: A Meta Analysis. Journal of Applied Psychology, 98(2), 268-309.

Reed, G. (2004). Toxic Leadership. Military Review, 84(4), 67-71.

Shufen, S. V. (2016, January 23). The Changing Face of Employee Loyalty. Business Times Singapore.

Tepper, B. (2000). Consequences of Abusive Supervision. The Academy of Management Journal, 43(2), 178-190.

Whicker, M. (1996). Toxic Leaders: When Organization Go Bad. Westport, VA: Quorum Book

Yucel, I., Mcmillan, A., \& Richard, O. C. (2014). Does CEO Transformational Leadership Influence Top Executive Normative Commitment? Journal of Business Research, 67(6), 1170-1177. 